\title{
Artigo
}

\section{Uma leitura da aproximação Cuba-EUA sob a doutrina Obama}

\author{
A Reading of Cuba-US approach under the Obama Doctrine \\ DOI: 10.5752/P.1809-6182.2016v13.n1.p8
}

Solange Reis ${ }^{1}$

Recebido em: 11 de maio de 2016

Aprovado em: 08 de junho de 2016

\begin{abstract}
Resumo
A restauração das relaçôes Cuba-EUA deriva de vários fatores, incluindo a reformulação da grande estratégia norte-americana. Sem o idealismo ou o realismo dos últimos 50 anos, Barack Obama adota pragmatismo na aproximação com Cuba, em resposta a novas forças sociais e à necessidade de recuperar a imagem dos Estados Unidos na regiäo.
\end{abstract}

Palavras-chave: Cuba. Estados Unidos. Doutrina Obama.

\section{Abstract}

The restoration of CUBA-US relations is due to several factors, including the reformulation of American grand strategy. Reducing the idealism and realism of the last 50 years, Barack Obama adopts pragmatism towards Cuba as a reply to new social forces and need to regain American image in the region.

Key-words: Cuba. United States. Obama Doctrine.

1. Pós-Doutoranda no Programa de Pós-Graduação em Relaçôes Internacionais San Tiago Dantas (UNESP, UNICAMP e PUC/SP), Doutora em Ciência Política pela Unicamp, Pesquisadora do Instituto Nacional de Ciência e Tecnologia para Estudos sobre os EUA e do CEDEC. orcid.org/0000-0002-9158-339X 
A rrematando uma série de simbolismos na retomada do diálogo entre Cuba e Estados Unidos, a histórica viagem de Barack Obama a Havana fechou um dos últimos capítulos da Guerra Fria. O prólogo ainda está por ser escrito, dependendo da superação de desconfianças recíprocas e da eliminação de barreiras diversas.

O principal obstáculo é o embargo comercial de mais de meio século, mas a questão dos dissidentes, as indenizaçōes por expropriaçóes pós-Revolução Cubana, o fechamento da base aérea e prisão de Guantánamo, e as diferentes interpretações sobre direitos humanos também serão desafiadores.

A ida a Cuba do primeiro presidente norte-americano em quase 88 anos, náo obstante, acresce um passo à normalização. O esforço não é unilateral; tampouco recente. Anunciada em dezembro de 2014, simultaneamente por Obama e o presidente cubano, Raúl Castro, a reaproximação foi precedida por um ano e meio de negociações bilaterais, contando inclusive com a intermediação do Vaticano. Mas o caminho começara bem antes, com a renúncia de Fidel Castro, em 2008, e açôes discretas da Casa Branca a partir do ano seguinte.

$\mathrm{O}$ novo padrão relacional evidencia mudanças domésticas nos dois países e o reordenamento do sistema internacional após a Guerra Fria, principalmente a reorientação da grande estratégia dos Estados Unidos em função de novos contextos internos e externos. Como seus antecessores, Obama procura manter uma posição de liderança mundial para seu país; o faz, porém, ajustando a ambição aos limites da multipolaridade, e da reconfiguração de forças sociais em âmbito doméstico, regional e global. As próximas páginas analisam a política externa para Cuba desta percepção.

\section{Qual Doutrina Obama?}

A poucos meses das eleiçóes presidenciais norte-americanas de 2016, especula-se sobre a essência da Doutrina Obama. Críticos consideram-na conformista, caracterizada por retraçáo e acomodação internacional em troca de ênfase nas políticas domésticas progressistas (DUECK, 2015, p. 14). Outros apostam na sua inexistência (FERGUSON, 2016). Apoiadores qualificam-na como a aceitação da definiçấo mais completa de responsabilidade (HACHIGIAN; SCHORR, 2013). Parte da opinião pública mundial identifica em Obama o agente da mudança para um mundo mais pacífico; outros o veem como "Bush com drones" (PILLALAMARRI; BERGSTROM, 2016). Diferentes leituras sobre segurança internacional em um contexto de multipolaridade, e de ascensão de Regiốes e atores não governamentais.

O fim do mandato não encerrará o dissenso sobre a qualidade de sua política exterior ao deixar a Casa Branca. Entre retrocessos e avanços, é possível classificá-la como reformista pragmática. Reforma no sentido de restaurar a liderança moral de uma superpotência em apuros estruturais; pragmatismo por aceitar os limites ao poder colocados por um sistema multipolar. Contrasta com as de seus antecessores imediatos, principalmente o desastroso unilateralismo da Doutrina Bush, que levou à perda de credibilidade e capacidade de influência na política internacional.

É importante observar que a grande estratégia dos países, incluindo as potências, não é estática e impermeável. Sua formulação e aplicação dependem do ajuste sensível entre as preferências de atores domésticos, os meios disponíveis e os fins desejados.

A grande estratégia compreende as orientaçóes gerais que pautam a conduta de um Estado em sua relação com o mundo. Essas coordenadas, 
contudo, se realizam através de políticas particulares, funcional e/ou espacialmente diferenciadas. Em todas elas, a questão central para o Estado é a mesma: como compatibilizar o geral e o particular, como integrar a ação desenvolvida em um dado setor ou em determinada área geográfica em uma perspectiva global cujo referente obrigatório é o conjunto da sociedade (CRUZ, 2012, p.18).

A reconciliação com Havana exemplifica a concepção de grande estratégia descrita acima e a doutrina aqui entendida como globalismo pragmático. Trata-se da descontinuidade do confronto aberto, haja vista que os presidentes norte-americanos anteriores a Obama adotaram, em menor ou maior grau, políticas conflitivas em relação a Cuba a partir da Revolução Cubana de 1959. No sentido de desacreditar o socialismo cubano ao longo dos anos, essas abordagens obtiveram graus variados de eficácia. Em tempos recentes, a política anti-Cuba mostrou-se infrutífera e prejudicial à imagem externa dos Estados Unidos.

Entre os fatores que levaram à necessidade de se reformular a estratégia, destacam-se os governos progressistas na América Latina nos últimos anos. Solidários a Cuba, dirigentes de esquerda e centro-esquerda na região pressionaram por um posicionamento cooperativo. Assim, a intransigência norte-americana tornou-se um passivo para seu projeto de liderança na região. $\mathrm{O}$ pacto com as elites políticas dominantes locais, que funcionara no contexto de absoluta hegemonia regional durante a construção da ordem liberal, enfraqueceu-se com as mudanças estruturais na economia e política globais no início do século atual. Em sua zona de influência continental, os Estados Unidos viram crescer a competição externa e a autonomia de potências médias da região.

Um efeito da perda de influência dos Estados Unidos na América Latina foi o espaço aberto para emergentes regionais e extrarregionais. O emprés- timo brasileiro para o projeto no Porto de Mariel (LIMA, 2014) e o crescimento das relaçóes econômicas China-Cuba são emblemáticos. Embora ainda pequenos, da ordem de US\$ 1,6 bilhão em 2015 (THE WASHINGTON POST, 2016), os investimentos chineses poderão crescer em segmentos críticos como infraestrutura de telecomunicaçóes, competindo com corporaçóes como a norte-americana AT\&T, que já negocia com a estatal Etecsa um acordo sobre telefonia móvel em Cuba.

Beneficiadas pelas permissóes do governo Obama para comercializar em Cuba, as norte-americanas de telecomunicação são vistas com muita desconfiança pelas autoridades cubanas. Motivos não faltam. O exemplo mais recente é o da startup Mobile Accord. Em 2009, um funcionário dessa empresa foi condenado em Cuba por conspiração. Alan Gross, que seria libertado como parte das negociaçóes de reaproximação em 2014, era responsável por importar e vender celulares por satélite, computadores e modens em Cuba. Para haver conspiração é preciso motivação política. Seria o caso ou mera paranoia cubana?

A Mobile Accord fora contratada pela U.S. Agency for International Aid (USAID) para ajudar na criação da rede social ZunZuneo, o Twitter cubano. Em novembro de 2014, um editorial do The New York Times (NYT) criticou as operações clandestinas para derrubar o regime em Cuba, citando o envolvimento de Gross. Segundo o NYT, a prisão do funcionário da Mobile Accord levou a questionamentos nos Estados Unidos sobre a legalidade da operação, mas a USAID manteve o programa até 2012, com a prudência de substituir os subcontratados norte-americanos por jovens latinos. O jornal concluiu que Washington não deveria esperar mais do que lograr influenciar a evolução de uma sociedade aberta em Cuba, o que seria mais provável de ocorrer por meio de fortes relações diplomáticas (IN CUBA..., 2014). 
O editorial parecia refletir os humores do Executivo: cerca de um mês depois da publicação, a reaproximação diplomática foi anunciada. Quiçá Obama convencera a si mesmo e aos mais intervencionistas de sua equipe sobre a ineficácia das velhas formas de interferência. Tantas ações, em surdina, haviam falhado sistematicamente em mudar o regime em Cuba e resultado na piora da imagem dos Estados Unidos. A partir de sua reeleição em 2012, coincidindo com fim do programa específico da USAID, o presidente passou a atos e falas de apoio aberto ao fortalecimento da sociedade civil e estímulo ao livre mercado em Cuba.

\section{Cuentapropismo e novos cubano-americanos}

Particularmente indicativa da nova estratégia foi o discurso feito em La Cervezeria, durante a visita a Havana. Reconhecendo as aberturas promovidas pelo governo castrista, o presidente disse que "mudanças em Cuba estão começando a acontecer" e "os Estados Unidos se sentem orgulhosos por ajudar". A fala seguiu com odes ao empreendedorismo, à boa vontade das corporaçóes norte-americanas e ao potencial do mercado consumidor de mais de 300 milhóes de habitantes em seu país (THE WHITE HOUSE, 2016). Na comitiva do presidente estavam membros do Presidential Ambassadors for Global Entrepreneurship, grupo criado em 2014 para incrementar o empreendedorismo dentro e fora do país, e da Spark Global Entrepreneurship Coalition, desenvolvida em 2015 com o objetivo de financiar e capacitar a livre iniciativa em países em desenvolvimento.

Formuladores de política externa implantaram o novo direcionamento em resposta a determinantes externos, como o aumento da competição em âmbito regional e extrarregional, e às transformações demográficas na comunidade cubano-ame- ricana. Desde o Cuban Adjustment Act de 1966, que facilita a residência permanente para imigrantes cubanos, mais de um milhão de pessoas emigraram para os Estados Unidos (RUSIN; ZONG; BATALAVA, 2015). Para efeito comparativo, Cuba possui pouco mais de 11 milhóes de habitantes.

A primeira geração formou um bloco étnico altamente politizado e conservador, que pressiona até hoje pelo não relaxamento da tensão entre os dois países. Além de desaprovar ideologicamente o governo cubano, este segmento não aceita o diálogo bilateral sem prévio acordo sobre as desapropriaçōes pós-Revolução. Se a história serve como parâmetro, a reunificação da Alemanha em 1990 indica o potencial explosivo de questôes desse tipo.

O comportamento anticastrista começou a arrefecer com a segunda e a terceira geração de cubanos-americanos. No caso da imigraçáo recente, a motivação é mais econômica do que política. Os descendentes nascidos nos Estados Unidos, especialmente os mais jovens, divergem de seus progenitores sobre a relação com Cuba. Em 2013, por exemplo, sessenta líderes de grupos representativos da nova geração enviaram uma carta ao secretário de Estado John Kerry condenando a postura tradicional contra Cuba (CHOW, 2013). A maior parte da populaçáo norte-americana também considera ultrapassada a velha política. A oposição à restauração das relações diplomáticas na visão da população decresceu de $49 \%$, em 1996, para 30\%, em 2009, percentual encontrado ainda hoje (CUBA..., 2016).

\section{Diplomacia comercial}

Enquanto pré-candidato em 2008, Obama manteve a abertura política como barganha em sua retórica, náo obstante advogar pelo relaxamento da tensão. Tal posicionamento correspondia à campanha presidencial desenvolvida sobre o mote de mudança e à percepção sobre as variaçóes geracio- 
nais, mas também à racionalidade prudente que já o caracterizava. Sua concorrente de partido era a senadora democrata Hillary Clinton, cujas ideias baseavam-se na concepçáo clintoniana de democracia como pilar para a ofensiva de globalização neoliberal (APELDOORN; GRAAF, 2016, p. 137). O afastamento radical dessa ideologia poderia comprometer a campanha do então senador.

Ciente das novas variáveis, Obama ajustou o tom quando eleito. Abandonou a assertividade pregressa em prol de diplomacia comercial e financeira. Da perspectiva norte-americana, era preciso que os Castros emitissem o primeiro sinal. Isto porque uma eventual iniciativa unilateral de Obama produziria fortes críticas pela oposição. A renúncia de Fidel em favor de seu irmão Raúl, naquele mesmo ano, por motivos de saúde, serviu como pretexto para as pequenas iniciativas da Casa Branca a partir de 2009.

Outra força motriz foi a pressão de setores econômicos. Em estado insípido de investimentos estrangeiros, Cuba representava um potencial tomador de capital em meio à crise financeira que solapava a economia norte-americana. Antes do desenvolvimento comercial das reservas de petróleo e gás de xisto nos Estados Unidos, as petrolíferas norte-americanas adiantavam-se no pedido pelo relaxamento das restriçóes comerciais alegando perda de mercado para empresas latinas e europeias, e riscos ambientais próximos à costa da Flórida.

Richard Feinberg (FEINBERG, 2012), integrante do séquito de ideólogos do governo, argumenta a favor de Investimento Estrangeiro Direto (IED) em Cuba. Segundo o autor, os IEDs produzem outros benefícios além dos financeiros, como transferência de tecnologia e conhecimento, bem estar social, capacitação profissional, oferta de empregos, exportaçóes, entre outros. Feinberg reconhece os riscos dos IEDs para os países importadores de capital, como a exposição a "vicissitudes de tendências globais de mercado e decisóes tomadas por conselhos corporativos distantes", mas insiste que os malefícios derivam de más políticas públicas do país receptor. "É hora de Cuba extrair sua cota justa de benefícios participando ativamente da economia" (FEINBERG, 2012, p. 73, tradução minha). ${ }^{2}$

Discutir malefícios ou benesses dos IEDs não cabe no escopo deste artigo. O fato é que a autorização do Federal Reserve Bank para a abertura de uma fábrica de tratores em Cuba exemplifica o planejamento naquele sentido. A Cleber Limited Liability Company (LLC), primeira indústria norte-americana a operar em Cuba em mais de 50 anos, obteve a permissáo em fevereiro do ano passado para fabricar e vender pequenos tratores para agricultores e cooperativas. $\mathrm{O}$ caminho para exportação de capitais, no entanto, necessitava da derrubada de um empecilho técnico e político. Tratava-se da exclusão de Cuba da lista de países apoiadores do terrorismo internacional, o que foi devidamente concluído pela Casa Branca em abril do mesmo ano. Ao contrário da suspensão do embargo, a retirada da lista não necessitava de aprovação legislativa.

No começo desse ano, o governo norte-americano permitiu a realização de voos comerciais entre os dois territórios. Dias antes da viagem de Obama, anunciou o fim de outras restriçóes comerciais, financeiras e de turismo. Outra alteração foi autorizar que instituiçôes financeiras norte-americanas processem transaçóes entre Cuba e terceiros países, aumentando o acesso cubano à economia global. Cidadáos cubanos não imigrantes que realizem serviços em caráter temporário para empresas nos Estados Unidos poderão abrir contas bancárias e fazer remessas para Cuba.

O Escritório de Indústria e Segurança do Departamento de Comércio emitirá licenças para a venda de itens que ajudem na exportaçáo de produtos manufaturados pelo setor privado cubano. $\mathrm{O}$ órgão também autorizará a importação de softwares

2. "It is time for Cuba to extract its rightful share of benefits from participating actively in the global economy". 
produzidos na ilha. Ademais, o Departamento do Tesouro expandirá as autorizaçōes para a presença física e institucional em Cuba de entidades com fins humanitários e educacionais. Atividades comerciais de empresas norte-americanas em Cuba serão estendidas do setor de telecomunicaçáo para o de transporte de carga e documentos.

Todas essas iniciativas corroem o embargo comercial no longo prazo; de imediato, incentivam os cuentapropistas, ou empreendedores individuais de pequeno porte em Cuba. Atitudes com baixo impacto político e grande efeito estruturante.

O engajamento direto dos Estados Unidos com empreendedores cubanos por meio de liberdade para viagem e mais remessas; acesso a serviços financeiros e bancários; aumento das exportaçóes de produtos com alta demanda pelos cuentapropistas na ilha; importação pelos Estados Unidos de bens e serviços cubanos produzidos de forma privada ou por cooperativas; e transferência de tecnologia e conhecimento são elementos encorajadores da nova política de Obama para Cuba. Essas mudanças têm o potencial de dar poder aos empreendedores - objetivo declarado dos Estados Unidos - e incentivar as reformas no setor privado já iniciadas, ainda que cautelosas, pelo governo cubano (HENKEN; VIGNOLI, 2015, p. 2, tradução minha). ${ }^{3}$

Os dois autores acima alertam para que o estímulo à livre iniciativa não seja usado como Cavalo de Troia para incitar a instabilidade política em Cuba. Sem a contrapartida do fim do embargo, que aliviaria a situaçáo macroeconômica do país de forma contundente, o fomento ao empreendi-

3. Direct U.S. engagement with Cuban entrepreneurs through freer travel and more remittances; access to banking and other financial services; increased exports of badly needed inputs to island cuentapropistas; the import of private or cooperatively produced Cuban goods and services to the U.S.; and technology and know-how transfer are all encouraging elements of Obama's new Cuba policy. These changes have the potential to both "empower" individual entrepreneurs-the stated goal of the U.S. policy shift-and incentivize the initial, if exceedingly cautious, private sector reforms already begun by the Cuban government. mento individual resultaria em retrocesso para os cuentapropistas. De forma que os primeiros anos do sucessor de Obama, seja republicano ou democrata, será um teste de resistência para o processo de reaproximaçáo, caso o novo presidente opte por uma condução mais idealista e menos pragmática.

\section{Acomodação}

Todas essas medidas não sugerem aceitação plena do regime cubano por parte dos Estados Unidos, empedernidos estes na tradição liberal, mas revelam uma dose expressiva de acomodação. No cálculo de ação, a democracia deixa de ser a condição sine qua non para ser o ganho marginal; abrir poros com soft power. Nesse sentido, a política para Cuba serve como microcosmo da grande estratégia de Obama em âmbito global. It is the commerce and the free market, stupid!, pode-se anedotizar.

Diante da assimetria de poder, o impacto em Cuba deverá ser colossalmente maior do que nos Estados Unidos, sendo elevada a chance de que o sistema político e econômico cubano não resista incólume à invasão de dólares e empreendimentos privados. Contrarrevoluçáo, conspirações, tentativas de assassinato de Fidel Castro, missóes clandestinas e a demonização de Cuba nos fóruns regionais e internacionais, comuns em outros tempos, cedem vez ao encorajamento da livre iniciativa na ilha. A fórmula é simples: facilitar o fluxo de bens, serviços e capital para Cuba na esteira do empreendedorismo nascente. Basicamente, minar o socialismo cubano sem o uso da força ou da conspiraçáo, procurando espaço nas esferas sociais e catapultando a transformação de baixo para cima.

Essas medidas rompem com o longo consenso bipartidário sobre o isolamento de Cuba. Democratas e republicanos votaram monoliticamente por décadas a favor de uma política anticastrista. Basta lembrar que foi no governo do democrata Bill 
Clinton que o Cuban Liberty and Democratic Solidarity Act, também conhecido como Helms-Burton Act, oficializou o embargo em forma de lei. É fato que, inicialmente contrário à lei, Clinton não teve alternativa política após a derrubada por Cuba de dois aviōes civis do Brothers to the Rescue, grupo cubano-americano de apoio a emigrantes que tentavam a travessia marítima para os Estados Unidos. Por outro lado, não compensava travar a queda de braço com o Congresso por um tema de menor estatura àquela altura da história, quando eldorados de expansão para o capitalismo abriam-se no Leste Europeu, Cáucaso e Ásia Central. Passada a Guerra Fria, Cuba decrescera em relevância estratégica.

Com uma política disfuncional, George W. Bush voltou uma casa no jogo, aprofundando o bloqueio e as barreiras de viagem para a ilha, dois elementos centrais para o isolamento do regime castrista.

Uma vez eleito, Obama adotou mecanismos para encerrar gradativamente o padráo de conflito e viabilizar a aproximação. No primeiro semestre de sua gestão, suspendeu as restriçôes de mobilidade e transferências financeiras de cubano-americanos para Cuba. Permitiu, igualmente, viagens para divulgação e comercialização de produtos médicos e agrícolas.

Em 2011, medidas executivas estenderam a permissão de viagem a representantes de instituiçóes religiosas, educacionais ou culturais. Apoiadores da iniciativa, como John Kerry, entáo presidente do Comitê do Senado para Relações Externas, acreditavam que a flexibilidade ajudaria a fortalecer o setor privado em Cuba. "Desde que o presidente Barack Obama assumiu o cargo, a Administração procurou um novo começo com Cuba. Como ele disse na semana passada, quando se trata de nossa relação com Cuba, temos que ser criativos, temos que ser atentos, e temos que continuar atualizando nossas políticas" (KERRY, 2012, tradução minha) ${ }^{4} \mathrm{~A}$ alçada de Kerry ao posto de secre-

4. Since President Obama took office, the Administration has started to search for a new beginning with Cuba. As he said tário de Estado, em 2013, permitiu tal abordagem, uma vez que sua antecessora, Hillary Clinton, ainda preservava certa retórica punitiva.

Pré-candidata democrata à presidência hoje, Clinton agora pega carona na bem executada estratégia e apoia a reaproximaçáo. Em discurso de campanha na Flórida, no ano passado, defendeu o fim imediato e definitivo do embargo (GOMES, 2015). $\mathrm{Na}$ ocasião, Clinton previa disputar as eleiçôes gerais com os republicanos Jed Bush ou Marco Rubio, populares na comunidade cubana. Bush deixou a corrida antes das primárias na Flórida, nas quais Rubio amargou um segundo lugar. $\mathrm{O}$ vitorioso no estado foi o histriônico Donald Trump, que concorda com boa parte da política de Obama para Cuba. Os resultados e ânimos eleitorais dizem muito sobre a atmosfera favorável ao fim do bloqueio, trazendo mais um desafio para os republicanos do mainstream.

O Partido Republicano possui maioria nas duas Casas atualmente, o que torna improvável a suspensão do embargo pelo $114^{\circ}$ Congresso. Este quadro poderá mudar após as próximas eleições, mas enquanto não houver permissão legislativa, a Casa Branca seguirá com as ordens executivas.

\section{Conclusão}

Após a primeira eleição de Obama, questionava-se se sua política externa seria marcada pelo idealismo wilsoniano ou por progressismo realista. A julgar por sua recente entrevista à revista The Atlantic, (GOLDBERG, 2016), ambas as orientaçôes doutrinárias o conduzem. Quando se trata de avançar a economia capitalista, recupera a versão wilsoniana de Porta Aberta. Naturalmente, na casa alheia. Se a questão é segurança nacional ou internacional, defende o uso da coerção apenas quan-

just last week, when it comes to our relationship with Cuba, we have to be creative, we have to be thoughtful, and we have to continue to update our policies 
do esgotada a persuasão diplomática. Para Obama, Cuba seria a prova de que a abordagem diplomática funciona bem mais do que o confronto. E conclui afirmando que a nova política para Cuba serve como trampolim para a recuperação da liderança dos Estados Unidos na América Latina.

Realista na prudência para high politics; idealista quando convém avançar o capitalismo transnacional que embasa a hegemonia; pragmático, contudo, na percepção de que a política não prescinde das fontes sociais. E estas possuem tempo próprio de maturação.

\section{REFERÊNCIAS}

APELDOORN, Bastiaan van; GRAAFF, Naná de. American grand strategy and corporate elite networks. New York: Routledge, 2016.

CHOW, Emily. Cuban americans denounce Florida legislators position of Cuba on the terrorist list. Washington DC: Latin American Working Group, 2013. Available: < http://www.lawg. org/action-center/lawg-blog/69-general/1207-cuban-americans-denounce-florida-legislators-position-of-cuba-on-the-terrorist-list\#sthash.AudNNfPw.dpuf $>$. Accessed: May 11, 2016.

CRUZ, Sebastiẫo C. V. Os Estados Unidos no desconcerto do mundo.

São Paulo: Editora Unesp, 2012.

CUBA. [S.1.]: Gallup, 2016. Available: <http://www.gallup. com/poll/1630/cuba.aspx>. Accessed: 8 May 2016.

DUEK, Colin. American grand strategy and corporate elite networks: the open door since the end of cold war. New York: Routledge, 2016.

FEINBERG, Richard E. The new cuban economy: what roles for foreign investments? [S.1.]: Latin American Initiative, 2012. Available: < http://www.brookings.edu/ //media/research/files/papers/2012/12/cuba-economy-feinberg/cuba-economy-feinberg-9.pdf>. Accessed: May 7, 2016.

FERGUSON, Niall. Barack Obama's revolution on foreign policy. The Atlantic, March 13, 2016.

GOLDBERG, Jeffrey. The Obama doctrine. The Atlantic. April, 2016. Available: <http://www.theatlantic.com/magazine/archive/2016/04/the-obama-doctrine/471525/>. Accessed: April 30, 2016.

GOMES, David. Hillary Clinton remarks at Florida International University. Miami: Cubanow, Aug. 1, 2015. Available: <http://cubanow.us/blog/hillary_clinton_remarks_at_florida_international_university/>. Accessed: May 11, 2016.
HACHIGIAN, Nina; SCHORR, David. The Responsibility Doctrine. The Washington Quarterly, n. 36:1 p. 73-91, 2013. Available: <http://csis.org/files/publication/TWQ_13Winter_ HachigianShorr.pdf>.Accessed: Feb. 20, 2016.

HENKEN, Ted A.; VIGNOLI, Gabriel.Enterprising Cuba: citizen empowerment, state abandonment, or U.S. business opportunity? Washington: Center for Latin American e Latino Studies, 2015. Available: <http://www.american.edu/clals/ upload/2015-AU-SSRC-Henken-Vignoli-Enterprising-Cuba-FINAL.pdf >. Accessed: Apr. 22, 2016.

HERRICK, Spokesperson Matt. Eight facts about ZunZuneo. [S.1.]: USAID, April $7^{\text {th, }}$ 2014. Available: <https://blog. usaid.gov/2014/04/eight-facts-about-zunzuneo/>. Accessed: Apr. 25 ${ }^{\text {th }}, 2016$.

IN CUBA, misadventures in regime change. The New York Times, Apr. 9, 2014. Available: <http://www.nytimes. com/2014/11/10/opinion/in-cuba-misadventures-in-regime-change.html?_r=0 _. Accessed: Nov. 20, 2015.

LEE, Carole E.; SCHWARTZ, Felicia. U.S. Competes with China for influence in Cuba: chinese firms lead efforts to build Cuba's internet infrastructure. The Wall Street Journal, Washington, March 18, 2016. Available: <http://www. wsj.com/articles/u-s-competes-with-china-for-influence-in-cuba-1458293405>. Accessed March 18, 2016.

LIMA, José Antonio. Por que o Brasil está certo ao investir em Cuba: o investimento no Porto de Mariel amplia o alcance do comércio e a área de influência do Brasil. Carta Capital, 2014. Available: <http://www.cartacapital.com.br/internacional/ por-que-o-brasil-esta-certo-ao-investir-em-cuba-1890.html 2 . Accessed May 11, 2016.

PILLALAMARRI, Akhilesh; BERGSTROM, Lisa A. 2016. Obama: George W. Bush with drones. The National Interest. Apr. 5, 2016. Available: <http://nationalinterest.org/feature/ obama-george-w-bush-drones-15684>. Accessed May 11, 2016. RUSIN, Sylvia; ZONG, Jie; BATALOVA, Jeanne. Cuban immigrants in the United States. Washington: Migration Information Source, April 7, 2015. Available: <http://www. migrationpolicy.org/article/cuban-immigrants-united-states $>$. Accessed May 11, 2016.

THE WHITE HOUSE. Remarks by president Obama at an entrepreneurship and opportunity event - Havana, Cuba. Washington, March 21, 2016. Available: <https://www.whitehouse.gov/the-press-office/2016/03/21/remarks-president-obama-entrepreneurship-and-opportunity-event-havana $>$. Accessed: Apr. 15, 2016.

U.S. DEPARTMENT OF STATE. Libertad Act. Washington, DC, 2001. Available: <http://20012009.state.gov/p/wha/rls/ fs/2001/2596.htm>. Accessed: April 10, 2016.

U.S. DEPARTMENT OF STATE. Remarks on U.S. policy in the western hemisphere. Washington, DC: Secretary of State , Nov. 18, 2013. Available: <http://www.state.gov/secretary/ remarks/2013/11/217680.htm>. Accessed May 13, 2016. 